\title{
Treatment of rice straw hemicellulosic hydrolysates with advanced oxidative processes: a new and promising detoxification method to improve the bioconversion process
}

\author{
João Paulo Alves Silva, Livia Melo Carneiro and Inês Conceição Roberto*
}

\begin{abstract}
Background: The use of lignocellulosic constituents in biotechnological processes requires a selective separation of the main fractions (cellulose, hemicellulose and lignin). During diluted acid hydrolysis for hemicellulose extraction, several toxic compounds are formed by the degradation of sugars and lignin, which have ability to inhibit microbial metabolism. Thus, the use of a detoxification step represents an important aspect to be considered for the improvement of fermentation processes from hydrolysates. In this paper, we evaluated the application of Advanced Oxidative Processes (AOPs) for the detoxification of rice straw hemicellulosic hydrolysate with the goal of improving ethanol bioproduction by Pichia stipitis yeast. Aiming to reduce the toxicity of the hemicellulosic hydrolysate, different treatment conditions were analyzed. The treatments were carried out according to a Taguchi $L_{16}$ orthogonal array to evaluate the influence of $\mathrm{Fe}^{+2}, \mathrm{H}_{2} \mathrm{O}_{2}, \mathrm{UV}, \mathrm{O}_{3}$ and $\mathrm{pH}$ on the concentration of aromatic compounds and the fermentative process.

Results: The results showed that the AOPs were able to remove aromatic compounds (furan and phenolic compounds derived from lignin) without affecting the sugar concentration in the hydrolysate. Ozonation in alkaline medium ( $\mathrm{pH}$ 8) in the presence of $\mathrm{H}_{2} \mathrm{O}_{2}$ (treatment A3) or $\mathrm{UV}$ radiation (treatment A5) were the most effective for hydrolysate detoxification and had a positive effect on increasing the yeast fermentability of rice straw hemicellulose hydrolysate. Under these conditions, the higher removal of total phenols (above 40\%), low molecular weight phenolic compounds (above 95\%) and furans (above 52\%) were observed. In addition, the ethanol volumetric productivity by $P$. stipitis was increased in approximately twice in relation the untreated hydrolysate.
\end{abstract}

Conclusion: These results demonstrate that AOPs are a promising methods to reduce toxicity and improve the fermentability of lignocellulosic hydrolysates.

Keywords: Ethanol, Pichia stipitis, Rice straw hemicellulosic hydrolysate, Advanced oxidative processes, Detoxification

\section{Background}

Lignocellulosic materials represent one of the most promising sources of renewable raw material for various biotechnological processes due to their low economic value and high availability. Composed of polysaccharides (cellulose and hemicellulose) and lignin, these materials are rigid and fibrous in structure [1-4]. A selective separation

\footnotetext{
*Correspondence: ines@debiq.eel.usp.br)

Deparatmento de Biotecnologia, Escola de Engenharia de Lorena, Universidade de São Paulo, Estrada Municipal do Campinho s/n, Cep, 12602-810 Lorena, SP, Brazil
}

of the main fractions are required to use these materials in biotechnological processes, which can be performed using different physical, chemical and biochemical pretreatment methods and various combinations thereof [5]. During acid hydrolysis, several toxic compounds are formed by the degradation of sugars and lignin. These compounds are mainly responsible for the toxicity of hemicellulosic hydrolysates due to their ability to inhibit microbial metabolism. Thus, the use of a detoxification step represents an important aspect to be considered for the improvement of fermentation processes from hydrolysates [6].

\section{Biomed Central}

(c) 2013 Silva et al.; licensee BioMed Central Ltd. This is an Open Access article distributed under the terms of the Creative Commons Attribution License (http://creativecommons.org/licenses/by/2.0), which permits unrestricted use, distribution, and reproduction in any medium, provided the original work is properly cited. 
Several methods have been proposed to reduce the concentration of toxic compounds to levels that would not inhibit the fermentation process [7-9]. These methods can be divided into the following three main groups: biological, physical and chemical. Biological treatments involve the use of microorganisms or enzymes that act on the toxic compounds present in the hydrolysate by changing their chemical structures [8,10]. The physical methods promote the removal of toxic compounds from the medium without changing their chemical structures. These methods are based on adsorption processes and include the use of activated charcoal [11], ion exchange resins [12], diatomaceous earth [13], or phase transfer processes such as solvent extraction [14] and evaporation [9]. Currently, the main chemical detoxification methods employed in hydrolysates treatment are based on the addition of reductive substances and $\mathrm{pH}$ modification. Reductive substances may lead to chemical modifications of the toxic inhibitor compounds, thereby changing the degree of toxicity [15]. The processes based on $\mathrm{pH}$ modification lead to a reduction in hydrolysate toxicity by two different mechanisms. The first mechanism is due to the $\mathrm{pH}$-dependent precipitation of toxic compounds, and the second method is attributed to the decomposition of certain compound inhibitors due to their chemical instability at certain $\mathrm{pH}$ values $[16,17]$. Many of the detoxification methods based on physical, chemical and biological processes can result in a considerable reduction to the sugar concentration; however these sugar's losses are undesirable for fermentation purposes [18-21].

A new, promising and little studied method for the detoxification of lignocellulosic hydrolysates is the use of advanced oxidative processes (AOPs). AOPs have been studied for the remediation of lignin derivatives from pulp and paper industry wastewater [22]. Such processes have the ability to degrade toxic and recalcitrant compounds, thereby reducing the toxicity of effluents and enhancing their susceptibility to biological agents. Therefore, it is possible to apply AOPs as a method of reducing the toxicity of lignocellulosic hydrolysates. Advanced oxidative processes (AOPs) can be defined as those methods where hydroxyl radicals $\left(\mathrm{HO}_{\bullet}\right)$ are produced in sufficient quantities to act as the main oxidizing agent [23]. The hydroxyl radical is a powerful oxidizing agent that is able to mineralize biorecalcitrant organic compounds or convert them into biodegradable compounds [24]. Due to its high reactivity, the hydroxyl radical must be generated in situ, which may be accomplished with a number of different processes [25]. Hydroxyl radicals can be generated as a result of a combination of strong oxidizing agents, such as hydrogen peroxide and ozone. Ultraviolet (UV) or visible radiation and catalysts such as metal ions and semiconductors can also be used to create hydroxyl radicals [26,27]. The reactions between hydroxyl radicals and organic molecules present in the medium can be classified into the following three classes according to their reaction mechanisms: hydrogen atom extraction, electrophilic addition and electron transfer [28].

The prevalence of a particular type of reaction in organic compound oxidation depends on multiple factors, including the compound concentration and the chemical structure [26]. Generally, electrophilic addition reactions tend to occur more quickly than the subtraction of hydrogen atoms or electron transfer in aromatic compounds and unsaturated hydrocarbons. The electrophilic nature of the hydroxyl radical can lead to a preferential attack of compounds with aromatic rings, which have a high electron density $[29,30]$.

The effluents from industrial cellulose pulps are composed mainly of phenolic and aromatic compounds resulting from the degradation of lignin and carbohydrates. Many authors have reported a reduction in toxicity and an increase in the biodegradability of different toxic pollutants through treatment by AOPs [31-33]. Although AOPs have been widely studied to reduce the toxicity of various types of industrial effluents, the use these methods to detoxify lignocellulosic hydrolysates is a field still unexplored; there being a great shortage of work in this area.

In this context, the present study aimed to evaluate AOPs as a method to detoxify rice straw hemicellulosic hydrolysates to improve the ethanol production by Pichia stipitis.

\section{Results and discussion}

\section{Characterization of rice straw hemicellulosic hydrolysate}

The Rice Straw Hemicellulosic Hydrolysate (RSHH) was obtained by dilute acid hydrolysis and concentrated by vacuum evaporation. The composition of the hydrolysate is shown in Table 1. As shown, the hydrolysate presented a total sugar concentration of approximately $160 \mathrm{~g} / \mathrm{L}$, with a ratio of 6:1:1 of xylose, glucose and arabinose. In addition to sugars (Table 1) compounds potentially harmful to the fermentation process, such as carboxylic acids, furans and phenolic compounds, were also identified. The RSHH contained approximately $2 \mathrm{~g} / \mathrm{L}$ acetic acid, whose origin is attributed to the acetyl groups present in the hemicellulose polymers that are released during hydrolysis. The presence of $211 \mathrm{mg} / \mathrm{L}$ furfural and $116 \mathrm{mg} / \mathrm{L}$ hydroxymethylfurfural (HMF) in RSHH demonstrates the partial degradation of xylose and glucose, respectively.

The rice straw hemicellulosic hydrolysate had a high concentration of phenolic compounds (approximately $12.9 \mathrm{~g} / \mathrm{L}$ ) compared to acetic acid (approximately $2 \mathrm{~g} / \mathrm{L}$ ) and furan $(327 \mathrm{mg} / \mathrm{L})$. Only $4 \%$ of the total phenolic compounds present in RSHH were identified by HPLC (Table 1). In fact, the chromatographic technique only 
Table 1 Composition of the rice straw hemicellulosic hydrolysate as its major constituents

\begin{tabular}{|c|c|c|}
\hline Components & Units & RSHH \\
\hline Total solids & $(g / L)$ & $305.0 \pm 1.9$ \\
\hline Ash & $(g / L)$ & $31.4 \pm 0.6$ \\
\hline
\end{tabular}

Carbohydrates and aliphatic acids

$\begin{array}{rlc}\text { Xylose } & (\mathrm{g} / \mathrm{L}) & 115.9 \pm 1.0 \\ \text { Glucose } & (\mathrm{g} / \mathrm{L}) & 20.8 \pm 0.1 \\ \text { Arabinose } & (\mathrm{g} / \mathrm{L}) & 21.2 \pm 0.2 \\ \text { Acetic acid } & (\mathrm{g} / \mathrm{L}) & 1.96 \pm 0.01\end{array}$

Furans

\begin{tabular}{|c|c|c|}
\hline Furfural & $(\mathrm{mg} / \mathrm{L})$ & $211 \pm 4$ \\
\hline Hydroxymethylfurfural & $(\mathrm{mg} / \mathrm{L})$ & $116 \pm 10$ \\
\hline \multicolumn{3}{|l|}{ Phenolic compounds } \\
\hline Total phenolic compounds & $(g / L)$ & $12.9 \pm 0.8$ \\
\hline \multicolumn{3}{|c|}{ Low molecular weight phenolic compounds } \\
\hline Ferulic acid & $(\mathrm{mg} / \mathrm{L})$ & $270 \pm 8$ \\
\hline p-coumaric acid & $(\mathrm{mg} / \mathrm{L})$ & $106 \pm 2$ \\
\hline Syringic acid & $(\mathrm{mg} / \mathrm{L})$ & $53 \pm 3$ \\
\hline Vanillic acid & $(\mathrm{mg} / \mathrm{L})$ & $32 \pm 4$ \\
\hline Vanillin & $(\mathrm{mg} / \mathrm{L})$ & $28 \pm 6$ \\
\hline Hydroxybenzoic acid & $(\mathrm{mg} / \mathrm{L})$ & $14 \pm 3$ \\
\hline \multicolumn{3}{|l|}{ Minerals } \\
\hline Sulfate & $(\mathrm{mg} / \mathrm{L})$ & $9998 \pm 1195$ \\
\hline K & $(\mathrm{mg} / \mathrm{L})$ & $5779 \pm 233$ \\
\hline $\mathrm{Fe}$ & $(\mathrm{mg} / \mathrm{L})$ & $1765 \pm 99$ \\
\hline $\mathrm{Mn}$ & $(\mathrm{mg} / \mathrm{L})$ & $1217 \pm 25$ \\
\hline $\mathrm{Mg}$ & $(\mathrm{mg} / \mathrm{L})$ & $923 \pm 40$ \\
\hline Phosphate & $(\mathrm{mg} / \mathrm{L})$ & $927 \pm 99$ \\
\hline $\mathrm{Cr}$ & $(\mathrm{mg} / \mathrm{L})$ & $332 \pm 50$ \\
\hline $\mathrm{Al}$ & $(\mathrm{mg} / \mathrm{L})$ & $266 \pm 23$ \\
\hline $\mathrm{Na}$ & $(\mathrm{mg} / \mathrm{L})$ & $195 \pm 36$ \\
\hline $\mathrm{Ca}$ & $(\mathrm{mg} / \mathrm{L})$ & $137 \pm 58$ \\
\hline $\mathrm{Zn}$ & $(\mathrm{mg} / \mathrm{L})$ & $30 \pm 4$ \\
\hline $\mathrm{Cu}$ & $(\mathrm{mg} / \mathrm{L})$ & $0.4 \pm 0.2$ \\
\hline
\end{tabular}

Chemical compositions of rice straw hemicellulosic hydrolysate obtained after concentration process (RSHH).

permits the identification of monomeric compounds. It is likely that $96 \%$ of the total phenol content can be attributed to polyphenolic structures. Among the compounds derived from the solubilized lignin in acidic medium, the hydrolysate contained vanillin $(28 \mathrm{mg} / \mathrm{L})$, p-coumaric acid $(106 \mathrm{mg} / \mathrm{L})$, vanilinic acid $(32 \mathrm{mg} / \mathrm{L})$, syringic acid $(53 \mathrm{mg} / \mathrm{L})$, ferulic acid $(270 \mathrm{mg} / \mathrm{L})$ and $\mathrm{p}-$ hydroxybenzoic acid (14 mg/L). These compounds have been suggested to be potential inhibitors to microbial metabolism [34].

\section{Detoxification treatment}

Aiming to evaluate the potential application of AOPs in reducing the toxicity of rice straw hemicellulosic hydrolysate, assays were conducted to study the influence of $\mathrm{Fe}^{+2}, \mathrm{H}_{2} \mathrm{O}_{2}$, UV irradiation, $\mathrm{O}_{3}$ and $\mathrm{pH}$. Each variable and combinations thereof was studied in terms of its ability to reduce the concentration of phenolic compounds (total and low molecular weight) and furans. The Pichia stipitis fermentability of the treated hydrolysates was also assessed for each condition.

\section{The effect of treatment on the sugar concentration}

There was no significant change in the concentration of sugars for all of the conditions evaluated (data not shown). This is a positive result; methods of detoxification based on physical, chemical and biological treatment often results in a considerable reduction in the concentration of sugars [18,19,21]. For example, Carvalho et al. [35] evaluated the detoxification of sugarcane bagasse hemicellulosic hydrolysate by activated charcoal and a combined system of activated carbon and ion exchange resin. The authors observed a 19\% and 40\% reduction in the xylose concentrations with activated carbon and the combined system, respectively. Mussatto, Santos and Roberto [21] evaluated the detoxification process for a rice straw hemicellulosic hydrolysate using activated carbon adsorption and observed that, the xylose concentrations were reduced by $4 \%$ to $18 \%$. In the present study, the low influence of the treatments by AOPs on the carbohydrates concentration may be related to the molecular structure of the sugars. The hydroxyl radical, the main oxidizing agent of AOPs, has a higher affinity for compounds with regions of high electron density, such as aromatic rings $[29,30]$. Such structures do not exist in sugar molecules.

\section{The effect of treatment on the concentration of phenolic and furan compounds}

Table 2 shows the percent reduction in the concentration of total furans (furfural and HMF), low molecular weight phenolic compounds (LMWPC) and total phenolic compounds after hydrolysate treatment. Hydrolysates were treated according to the assay conditions specified by the experimental design of Taguchi.

In essentially every trial of the experimental design, changes in the concentration of total phenolic compounds, furans and LMWPC were observed. These findings indicate that this response is strongly influenced by these variables. The greatest reduction in the total phenolic concentration (35-47\%) occurred in those treatments performed in the presence of ozone (assays A1, A3, A5, A7, A9, A11, A13 and A15). These results suggest that ozone imparts a great influence on the reduction of total phenolics in hemicellulosic hydrolysates. Similar to the observed reduction in phenolics, the highest reductions in 
total furan (33 to 55\%) and LMWPC (60 to 96\%) concentrations were observed in assays containing ozone (A1, A3, A5, A7, A9, A11, A13 and A15). Among the ozone-containing assays, those with basic $\mathrm{pH}$ (A3, A5, A9 and A15) showed reductions of approximately 53\% and 95\% for furans and LMWPC, respectively. This behavior demonstrates a positive interaction between the alkaline $\mathrm{pH}$ and the presence of ozone, resulting in favorable conditions for the removal of phenols and furan. Phenolic compounds become more susceptible to oxidative degradation at alkaline $\mathrm{pH}$. In basic conditions phenolate ions are formed by the dissociation of the hydroxyl proton from the benzene ring, thereby increasing the electron density of the aromatic ring, which becomes more susceptible to oxidation [36].

In the present study, we demonstrate that AOPs preferentially remove aromatic compounds, such as furans and phenolic compounds, and do not interfere with the sugar concentration. In fact, some authors suggest that molecular structures with high electron densities, such as aromatic rings, can be preferentially oxidized by such processes [29,37]. The processes of Fenton (characterized by the presence of $\mathrm{Fe}^{+2}$ and $\mathrm{H}_{2} \mathrm{O}_{2}$ at acidic $\mathrm{pH}$ - assay A04), UV-peroxide (assay A10), and photolysis (assay A14) have been shown to reduce the levels of furans (5-18\%) and LMWPC (8-19\%) present in the hydrolysate. However, these observed reductions were mild compared with those shown in other assays of the experimental design.

\section{Evaluation of the treated hydrolysate fermentability by Pichia stipitis}

The profiles of sugar consumption and ethanol production by Pichia stipitis in rice straw hemicellulosic hydrolysates (containing approximately $90 \mathrm{~g} / \mathrm{L}$ sugar in a 6:1 proportion of xylose and glucose) after AOP detoxification are shown in Figures 1 and 2. There were a large number of assays performed; thus, to better understand the data, the experiments were divided into two groups. The hydrolysates treated in acidic medium (initial pH 3) were classified as group (a), and those treated in basic medium (initial pH 8) were designated as group (b). Fermentation in the hydrolysates of groups (a) and (b) was compared. In addition, the fermentation profiles with semi-synthetic medium and an untreated hydrolysate were included as controls.

Figure 1 shows the consumption of sugars (glucose and xylose) by the yeast $P$. stipitis in hydrolysates treated with different conditions according to our experimental design. In general, the $\mathrm{pH}$ was an important variable affecting hydrolysate fermentability. The use of alkaline conditions for hydrolysate treatment favored both sugar consumption and ethanol production. Yeast cultured in hydrolysates treated with acidic $\mathrm{pH}$ (Figure 1a), with the exception of treatment A7, did not exhibit improved sugar consumption compared to untreated hydrolysates. For example, yeast cultivated in assays A4, A6, A13 and A16 exhibited similar or lower sugar consumption compared to those cultivated in the untreated hydrolysate whereas in assays A1, A10 and A11 any sugar consumption was observed. On contrary, in the hydrolysates treated with alkaline conditions (Figure 1b) the sugar utilization was favored. In assays A3, A5 and A12, 90\% of the sugars were utilized by the yeast in 96 hours, and in assays A9, A14 and A 15 , approximately $82 \%$ of the sugars were consumed during the same time. Although this group of assays showed a lower sugar intake than fermentation in semisynthetic medium (100\% in 96 hours), there was a considerable increase in consumption compared to fermentation in the untreated hydrolysate (51\% in 96 hours).

Regarding ethanol production (Figure 2), it appears that among the treatments carried out in acid $\mathrm{pH}$ (Figure 2a), only assay A7 favored ethanol production by $P$. stipitis. Under this condition, the yeast produced approximately $22 \mathrm{~g} / \mathrm{L}$ of ethanol after 120 hours, whereas the untreated hydrolysate produced only $15 \mathrm{~g} / \mathrm{L}$ during the same fermentation time. This increase in ethanol production corresponds to a $50 \%$ increase due to treatment. Similar to fermentation in the untreated hydrolysate, the yeast from assays A4 and A6 yielded only $13 \mathrm{~g} / \mathrm{L}$ of ethanol after 120 hours. On the other hand, in assays A13 and A16, the yeast underwent a long lag phase of growth, and as a consequence, the ethanol production started after 72 hours of fermentation and reached concentrations of $9 \mathrm{~g} / \mathrm{L}$ and $14 \mathrm{~g} / \mathrm{L}$, respectively. The lowest concentrations of ethanol, nearly $3 \mathrm{~g} / \mathrm{L}$ (after 120 hours), were observed in assays A1, A10 and A11 in which the yeast were not able to efficiently consume sugars (Figure 1a).

Compared to untreated hydrolysates, yeast showed an increase in ethanol production in all treatments performed in alkaline conditions (Figure $2 \mathrm{~b}$ ). The hydrolysates treated in assays A3 and A5 produced ethanol up to $26 \mathrm{~g} / \mathrm{L}$ after 72 hours of fermentation. This concentration is almost the same as that observed in semi-synthetic medium and is approximately twice the value found for the untreated hydrolysate cultivated for the same fermentation time (approximately $14 \mathrm{~g} / \mathrm{L})$.

In assays A9, A12, A14 and A15, ethanol concentrations near $23 \mathrm{~g} / \mathrm{L}$ were reached after 72 hours of cultivation. This concentration corresponds to a $60 \%$ increase in ethanol production over the untreated hydrolysate fermented for the same length of time. Among the treatments carried out in alkaline medium, assays A2 and A8 had the lowest ethanol concentration, showing an ethanol production profile very similar to that of the untreated hydrolysate fermented for 48 hours. However, after 72 hours of fermentation, A2 
Table 2 Experimental design and results obtained in the detoxification treatment and during the fermentation of hydrolysate treated

\begin{tabular}{|c|c|c|c|c|c|c|c|c|c|c|c|c|c|c|c|c|c|c|c|}
\hline \multirow[t]{3}{*}{ Assays } & \multicolumn{15}{|c|}{ Experimental conditions (Real values) } & \multicolumn{3}{|c|}{ Reduction (\%) } & \multirow{3}{*}{$\begin{array}{l}\mathrm{Qp}_{\mathrm{p}} \\
* * \\
(\%)\end{array}$} \\
\hline & A & B & $A B$ & C & $A C$ & $\mathrm{BC}$ & $\mathrm{DE}$ & D & AD & BD & CE & CD & $\mathrm{BE}$ & $\mathrm{AE}$ & E & Furans & LMWPC & Total phenolics & \\
\hline & $\mathrm{Fe}^{+2}(\mathrm{mg} / \mathrm{L})$ & $\mathrm{H}_{2} \mathrm{O}_{2}(\mathrm{mg} / \mathrm{L})$ & & UV & * & & & $\mathrm{O}_{3}(\mathrm{mg} / \mathrm{L})$ & * & & * & & * & * & $\mathrm{pH}$ & & & & \\
\hline A1 & $2(50)$ & $2(1000)$ & 2 & 2 (present) & 2 & 2 & 1 & $2(500)$ & 2 & 2 & 1 & 2 & 1 & 1 & $1(\mathrm{pH} \mathrm{3})$ & 44 & 70 & 35 & 7 \\
\hline A2 & $2(50)$ & $2(1000)$ & 2 & 2 (present) & 2 & 2 & 1 & $1(0)$ & 1 & 1 & 2 & 1 & 2 & 2 & $2(\mathrm{pH} 8)$ & 3 & 23 & 1 & 49 \\
\hline $\mathrm{A} 3$ & $2(50)$ & $2(1000)$ & 2 & 1 & 1 & 1 & 2 & $2(500)$ & 2 & 2 & 1 & 1 & 2 & 2 & $2(\mathrm{pH} 8)$ & 52 & 95 & 40 & 99 \\
\hline $\mathrm{A} 4$ & $2(50)$ & $2(1000)$ & 2 & 1 & 1 & 1 & 2 & $1(0)$ & 1 & 1 & 2 & 2 & 1 & 1 & $1(\mathrm{pH} 3)$ & 11 & 16 & -10 & 27 \\
\hline A5 & $2(50)$ & $1(0)$ & 1 & 2 (present) & 2 & 1 & 2 & $2(500)$ & 2 & 1 & 2 & 2 & 1 & 2 & $2(\mathrm{pH} 8)$ & 55 & 96 & 47 & 98 \\
\hline A6 & $2(50)$ & $1(0)$ & 1 & 2 (present) & 2 & 1 & 2 & $1(0)$ & 1 & 2 & 1 & 1 & 2 & 1 & $1(\mathrm{pH} \mathrm{3})$ & 14 & 16 & 4 & 29 \\
\hline A7 & $2(50)$ & $1(0)$ & 1 & 1 & 1 & 2 & 1 & $2(500)$ & 2 & 1 & 2 & 1 & 2 & 1 & $1(\mathrm{pH} 3)$ & 33 & 60 & 43 & 50 \\
\hline A8 & $2(50)$ & $1(0)$ & 1 & 1 & 1 & 2 & 1 & $1(0)$ & 1 & 2 & 1 & 2 & 1 & 2 & $2(\mathrm{pH} 8)$ & -3 & 11 & -7 & 56 \\
\hline A9 & $1(0)$ & $2(1000)$ & 1 & 2 (present) & 1 & 2 & 2 & $2(500)$ & 1 & 2 & 2 & 2 & 2 & 1 & $2(\mathrm{pH} 8)$ & 50 & 95 & 41 & 66 \\
\hline $\mathrm{A} 10$ & $1(0)$ & $2(1000)$ & 1 & 2 (present) & 1 & 2 & 2 & $1(0)$ & 2 & 1 & 1 & 1 & 1 & 2 & $1(\mathrm{pH} \mathrm{3})$ & 18 & 19 & -12 & 6 \\
\hline A11 & $1(0)$ & $2(1000)$ & 1 & 1 & 2 & 1 & 1 & $2(500)$ & 1 & 2 & 2 & 1 & 1 & 2 & $1(\mathrm{pH} 3)$ & 41 & 64 & 44 & 4 \\
\hline $\mathrm{A} 12$ & $1(0)$ & $2(1000)$ & 1 & 1 & 2 & 1 & 1 & $1(0)$ & 2 & 1 & 1 & 2 & 2 & 1 & $2(\mathrm{pH} 8)$ & -4 & 23 & 4 & 88 \\
\hline A13 & $1(0)$ & $1(0)$ & 2 & 2 (present) & 1 & 1 & 1 & $2(500)$ & 1 & 1 & 1 & 2 & 2 & 2 & $1(\mathrm{pH} \mathrm{3})$ & 40 & 63 & 42 & 20 \\
\hline A14 & $1(0)$ & $1(0)$ & 2 & 2 (present) & 1 & 1 & 1 & $1(0)$ & 2 & 2 & 2 & 1 & 1 & 1 & $2(\mathrm{pH} 8)$ & 5 & 8 & -11 & 82 \\
\hline A15 & $1(0)$ & $1(0)$ & 2 & 1 & 2 & 2 & 2 & $2(500)$ & 1 & 1 & 1 & 1 & 1 & 1 & $2(\mathrm{pH} 8)$ & 54 & 95 & 44 & 79 \\
\hline A16 & $1(0)$ & $1(0)$ & 2 & 1 & 2 & 2 & 2 & $1(0)$ & 2 & 2 & 2 & 2 & 2 & 2 & 1 (pH 3) & -2 & 5 & -6 & 32 \\
\hline
\end{tabular}

$Q_{p}$ $\%$

* Columns used in error estimation. ** Percentage in relation to that obtained in the semi-synthetic medium fermentation $\left(\mathrm{Q}_{\mathrm{p}}=0.36 \mathrm{~g} / \mathrm{L} \mathrm{h}\right)$.

Taguchi $\mathrm{L}_{16}$ experimental array, with different conditions of treatment by homogeneous AOPs evaluated, and responses: reduction of furans, low molecular weight phenolic compounds (LMWPC) and total phenols as well as the volumetric ethanol productivity by Pichia stipitis (expressed as a percentage relative to productivity obtained through the same conditions in semi-synthetic medium fermentation, $Q_{p}=0.36 \mathrm{~g} / L$.h). The standard deviation was less than $5 \%$. 

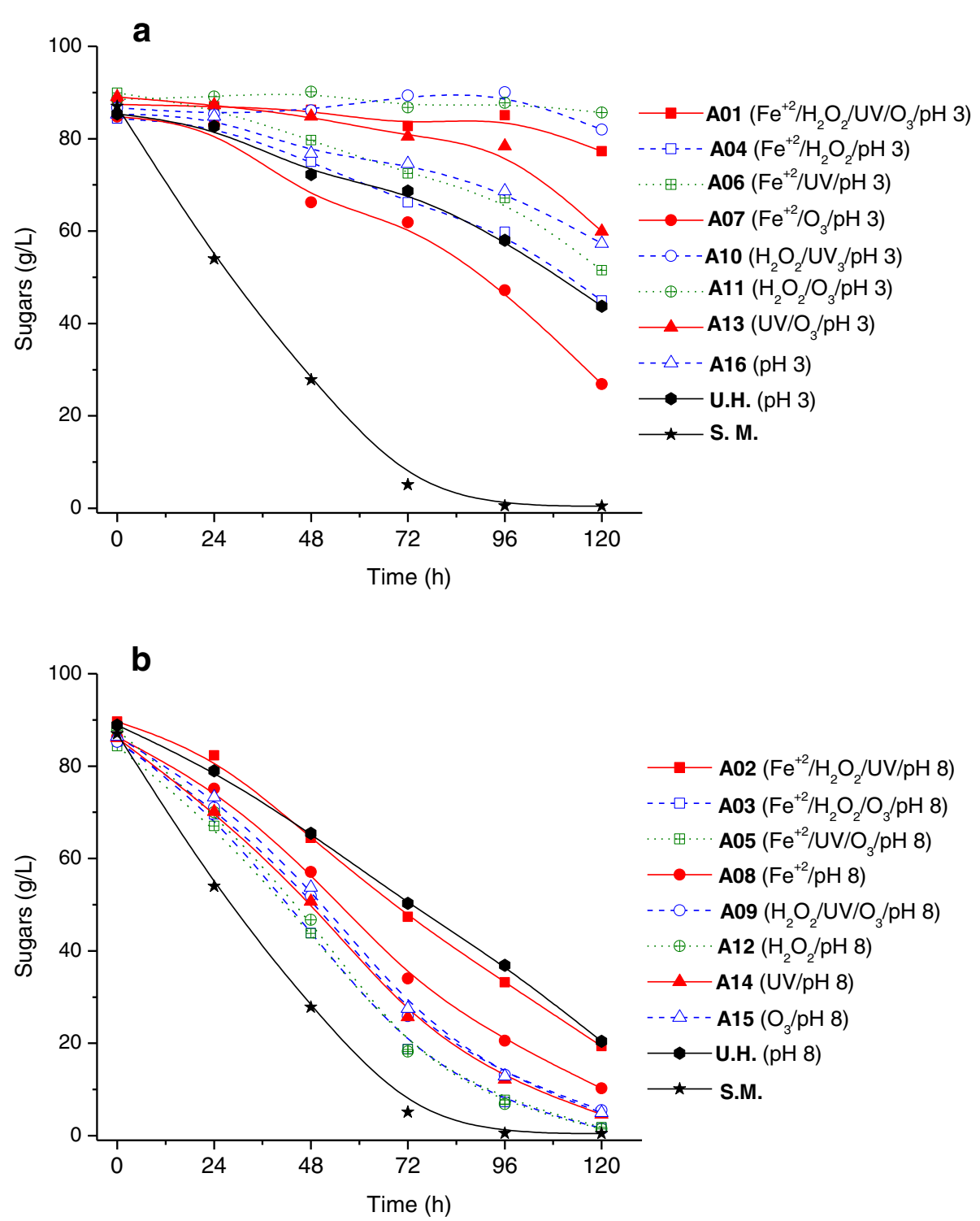

Figure 1 Sugar consumption by Pichia stipitis in the hydrolysate treated in different conditions of experimental design. Sugar consumption during the fermentations by P. stipitis in semi-synthetic medium (S.M.), untreated rice straw hemicellulosic hydrolysate (U.H.) and the hydrolysate treated by AOPs homogeneous under different conditions of the experimental design, where: (a) treatments performed at pH 3, (b) treatments performed at $\mathrm{pH} 8$. The standard deviation was less than $5 \%$ of the mean values of sugars consumption.

and $\mathrm{A} 8$ assays showed an increase in ethanol concentration of $18 \%$ and $33 \%$, respectively.

In general, the hydrolysates treated with AOPs under acidic conditions ( $\mathrm{pH}$ 3) exhibited reduced sugar consumption and ethanol production with respect to the untreated hydrolysate, even the assays A1, A11 and A13, which showed considerable reduction in the concentration of total phenols, LMWPC and furans. This result indicates that the degradation of these compounds may have resulted in more toxic products that may have been more harmful to the fermentation process. On contrary, a reduction in hydrolysate toxicity occurred in the treatments performed at a basic $\mathrm{pH}(\mathrm{pH} 8)$. This trend may be related to specific $\mathrm{pH}$-dependent mechanisms of attack of the hydroxyl radicals, which may lead to various degradation products. An example of these different degradation mechanisms is the formation of phenolate ions by the dissociation of a proton from the aromatic ring's hydroxyl, which occurs under alkaline conditions. The formation of these ions leads to an increase in the electron density of the aromatic ring, making it more susceptible to oxidation [36]. As with the hydroxyl group of the aromatic ring, different groups attached to the ring can dissociate at different $\mathrm{pH}$ values, thereby affecting the 

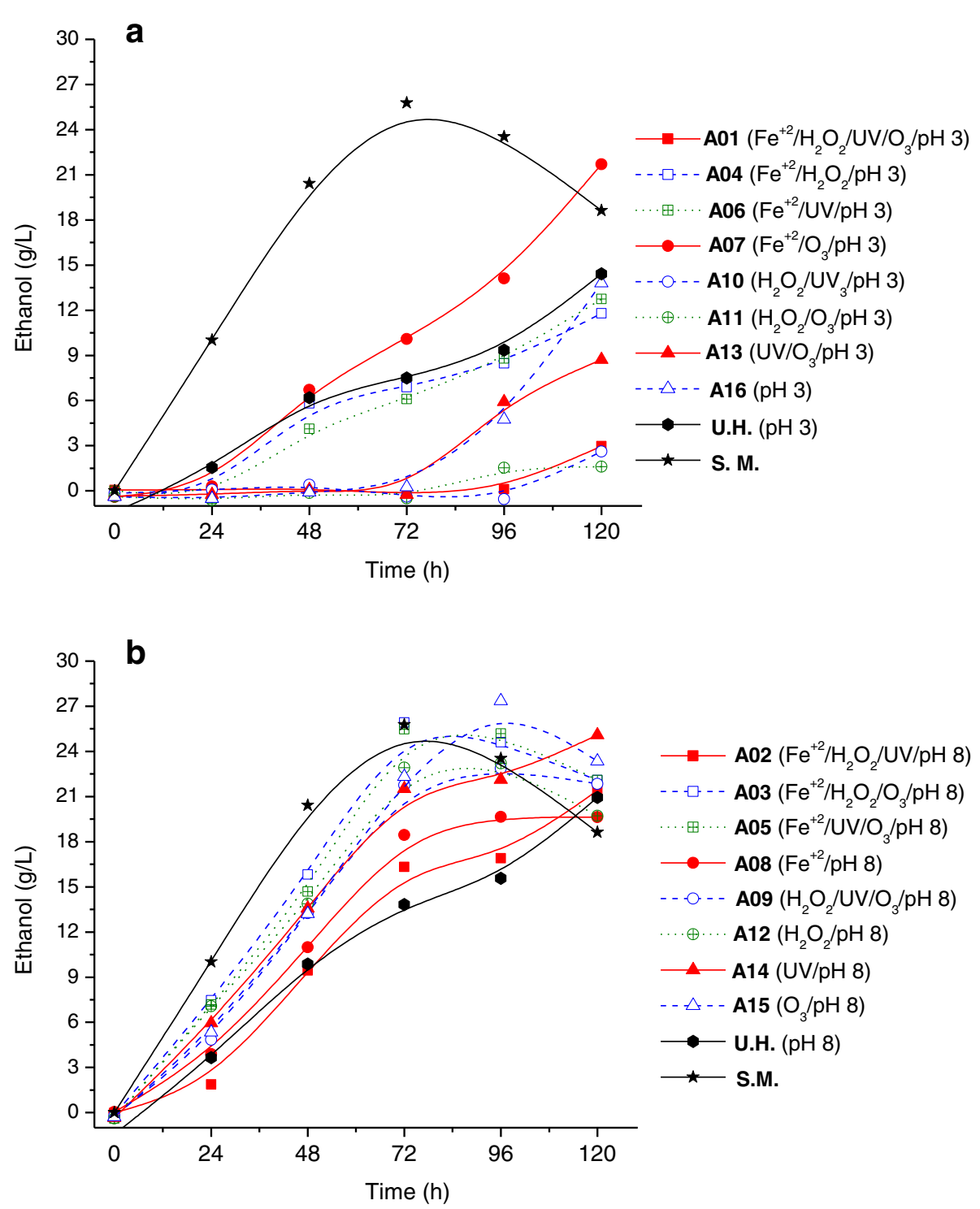

Figure 2 Ethanol production by Pichia stipitis in hydrolysate treated in different conditions of experimental design. Consumption of sugars (xylose and glucose in the proportion of 6:1) during the fermentations by P. stipitis in semi-synthetic medium (S.M.), untreated rice straw hemicellulosic hydrolysate (U.H.) and the hydrolysate treated by AOPs homogeneous under different conditions of the experimental design, where: (a) treatments performed at pH 3, (b) treatments performed at pH 8. The standard deviation was less than $5 \%$ of the mean values of ethanol production.

highly electron-rich regions of the molecules [38]. These variations in electronegativity for aromatic compounds can interfere with the orientation of hydroxyl radical attack, which is electrophilic in nature [29].

Figure 3 shows the ethanol volumetric productivity $\left(\mathrm{Q}_{\mathrm{P}}\right)$ and ethanol yield (expressed as\% of theoretical maximum based on total content of fermentable sugars) for fermentation by P. stipitis in an untreated hydrolysate, in hydrolysates treated by AOPs and in a semi-synthetic medium. The values of $Q_{P}$ varied from 0.02 to $0.36 \mathrm{~g} / \mathrm{L} . \mathrm{h}$, demonstrating that the different treatment conditions greatly influenced this parameter. The highest values for volumetric productivity (approximately $0.36 \mathrm{~g} / \mathrm{L} . \mathrm{h}$ ) were achieved in assays A3 and A5, which yielded up to $98 \%$ of the productivity obtained using a semi-synthetic medium. These two assays also showed elevated levels for the removal of total phenols (up to 47\%), LMWPC (up to 96\%) and furans (up to 55\%). Tests A1, A10, A11 and A13 had values of $Q_{P}$ less than $0.07 \mathrm{~g} / \mathrm{L} . \mathrm{h}$, which is less than that observed from the untreated hydrolysate. This low $Q_{\mathrm{p}}$ may be due to the formation of more toxic compounds. Similar to the behavior observed for $\mathrm{Q}_{\mathrm{B}}$ the values of ethanol yield showed a large variation (4 a $60 \%$ of maximum theoretical based on substrate 


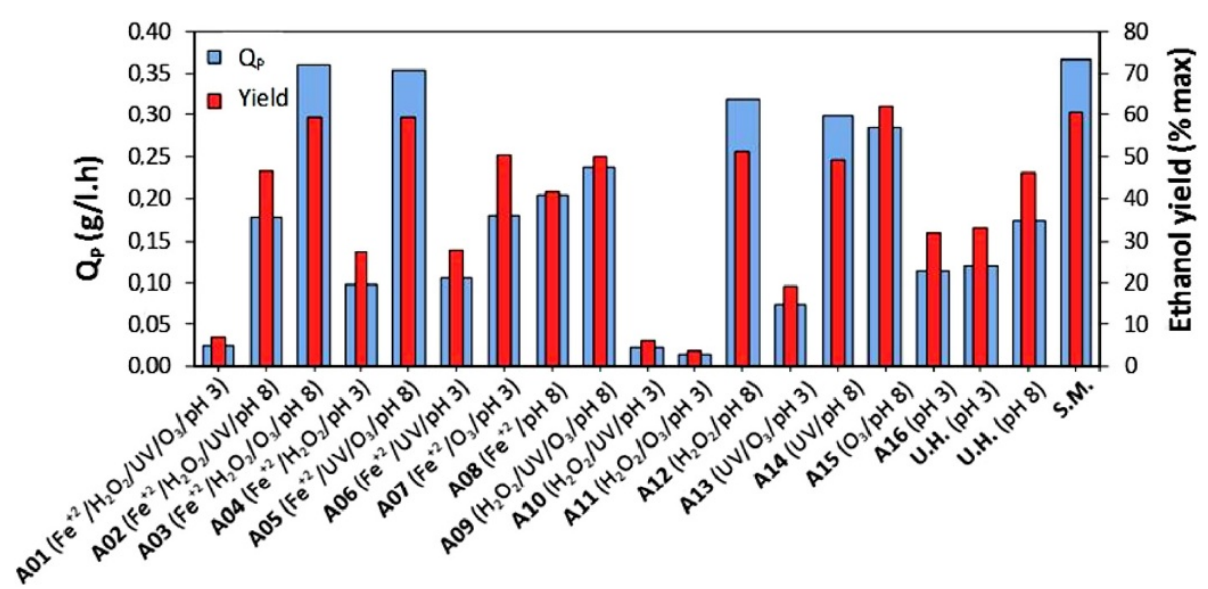

Figure 3 Fermentation parameter of Pichia stipitis cultivation in the different conditions of the experimental design. Ethanol volumetric productivity $(\square)$ and ethanol yield expressed as \% of theoretical maximum based on total content of fermentable sugars ( $\square$ ), observed in fermentations by $P$. stipitis in semi-synthetic medium, untreated rice straw hemicellulosic hydrolysate and the hydrolysate treated by AOPs homogeneous under different conditions of the experimental design.

content). In general, the fermentations of hydrolysate treated in $\mathrm{pH} 3$ showed the same or lower ethanol yields when compared to untreated hydrolysate, whereas the treatments carried in alkaline conditions $(\mathrm{pH} 8)$ resulted in improvements on ethanol yields. The highest values for ethanol yield (approximately $60 \%$ of theoretical maximum ethanol) were achieved in assays A3, A5 and A15, which were similar to that obtained using a semisynthetic medium.

These results demonstrate that the AOPs mediated detoxification of rice straw hemicellulosic hydrolysates can affect the hydrolysate fermentability to different degrees. The greatest impact of treatment occurred on the volumetric productivity of the fermentation process.

\section{Statistical analysis}

We used a statistical analysis to identify the most important factors to influence the detoxification of rice straw hemicellulosic hydrolysates by AOPs. In this analysis, we evaluated the effects of $\mathrm{Fe}^{+2}(\mathrm{~A}), \mathrm{H}_{2} \mathrm{O}_{2}$, (B), UV irradiation (C), $\mathrm{O}_{3}(\mathrm{D})$ and $\mathrm{pH}(\mathrm{E})$. The following combinations of factors were also evaluated: $\mathrm{AB}\left(\mathrm{Fe}^{+2} /\right.$ $\mathrm{H}_{2} \mathrm{O}_{2}$ - the Fenton process), $\mathrm{BC}\left(\mathrm{H}_{2} \mathrm{O}_{2} / \mathrm{UV}\right)$, $\mathrm{DE}\left(\mathrm{O}_{3} / \mathrm{pH}\right)$, $\mathrm{BD}\left(\mathrm{H}_{2} \mathrm{O}_{2} / \mathrm{O}_{3}\right)$ and $\mathrm{CD}\left(\mathrm{UV} / \mathrm{O}_{3}\right)$. The observed responses were the percent reduction in the concentrations of furans (furfural and HMF), LMWPC and total phenolics and changes in the ethanol volumetric productivity were measured for the fermentation of $P$. stipitis in hydrolysates from each treatment.

The statistical significance of the main effects and their interactions on the different responses were verified using an analysis of variance (ANOVA) test, presented in Table 3. According to the ANOVA (design $\mathrm{L}_{16}$ ), the percentages of variation in the concentrations of furans, total phenolics and LMWPC showed high correlation coefficients (97, 99 and 95\%, respectively). Thus, the observed variation can be explained by the factors that were evaluated. Ozone treatment was responsible for more than $87 \%$ of all the observed variation showing a positive effect on the removal of furans, total phenolics and LMWPC.

Statistical analysis showed that for furan reduction, $\mathrm{O}_{3}$ (D) and the combination of $\mathrm{O}_{3}$ and $\mathrm{pH}(\mathrm{DE})$ were significant with confidence level of $99 \%$, and UV radiation (C) was significant with confidence level of $95 \%$. For LMWPC reduction, $\mathrm{O}_{3}(\mathrm{D}), \mathrm{pH}(\mathrm{E})$ and the combination of $\mathrm{O}_{3}$ and $\mathrm{pH}(\mathrm{DE})$ were considered significant with a confidence level of $99 \%$. In addition, the $\mathrm{H}_{2} \mathrm{O}_{2}$ influence (factor B) was also significant, at a level of $95 \%$ confidence. Regarding the total phenolics, only ozone was significant with a confidence level of $99 \%$. All these significant variables showed positive effects on furans, LMWPC and total phenolics removal.

The volumetric productivity $\left(\mathrm{Q}_{\mathrm{P}}\right)$ of a fermentation process is an important parameter because it relates the concentration of the product formed with the time required for production. This results in an interesting basis for comparisons. To evaluate the influence of different hydrolysate treatments on yeast fermentability, the relationship between the ethanol volumetric productivity was used as the response variable. This response was compared to the productivity obtained from fermentation in semi-synthetic medium under the same conditions $(100 \%$ corresponds to the same productivity 
Table 3 Analysis of variance for the response evaluated in the experimental design

\begin{tabular}{|c|c|c|c|c|c|}
\hline \multirow[t]{2}{*}{ Source of variation } & \multicolumn{4}{|c|}{  } & \multirow{2}{*}{$\begin{array}{l}\text { Taguchi } \mathrm{L}_{8} \\
\mathrm{Q}_{\mathrm{p}}(\%)^{* * * *}\end{array}$} \\
\hline & Furans reduction & LMWPC & Total phenolics reduction & $Q_{p}(\%)^{* * * *}$ & \\
\hline $\mathrm{A}-\mathrm{Fe}^{+2}$ & 0.1 & 0.1 & 0.0 & 0.6 & 0.8 \\
\hline $\mathrm{B}-\mathrm{H}_{2} \mathrm{O}_{2}$ & 0.3 & $0.8^{* *}$ & 0.1 & 3.8 & 0.9 \\
\hline$A B$ & 0.0 & 0.0 & 0.6 & 0.0 & 0.0 \\
\hline$C-U V$ & $1.9^{* *}$ & 0.2 & 0.0 & 2.3 & 3.9 \\
\hline$B C$ & 0.2 & 0.0 & 0.3 & 4.0 & $71.8^{* *}$ \\
\hline $\mathrm{DE}$ & $7.3^{*}$ & $4.4^{*}$ & 0.0 & 2.4 & - \\
\hline $\mathrm{D}-\mathrm{O}_{3}$ & $87.8^{*}$ & $87.9^{*}$ & $95.5^{*}$ & 1.0 & $22.2^{* * *}$ \\
\hline $\mathrm{BD}$ & 0.1 & 0.3 & 0.3 & 0.6 & - \\
\hline$C D$ & 0.6 & 0.0 & 0.0 & 0.0 & - \\
\hline $\mathrm{E}-\mathrm{pH}$ & 0.1 & $5.9^{*}$ & 0.2 & $74.6^{*}$ & - \\
\hline $\mathrm{R}^{2}(\%)$ & 97.0 & 99.0 & 95.5 & 74.6 & 94.0 \\
\hline
\end{tabular}

* Significant at $99 \%$ confidence level; ${ }^{* *}$ Significant at $95 \%$ confidence level; ${ }^{* * *}$ Significant at $90 \%$ confidence level. ${ }^{* * *}$ Percentage in relation to that obtained in the semi-synthetic medium fermentation $\left(Q_{P}=0.36 \mathrm{~g} / \mathrm{L} . \mathrm{h}\right)$.

Analysis of variance of the main effects and of its interactions factors on the responses: reductions concentrations of furans, low molecular weight phenolic compounds (LMWPC) and total phenolics, besides of the ethanol volumetric productivity by Pichia stipitis $\left(\mathrm{Q}_{\mathrm{p}}\right)$, for the original design (Taguchi $\left.\mathrm{L}_{16}\right)$ and ethanol volumetric productivity to planning referent to process at alkaline $\mathrm{pH}$ only (Taguchi $\mathrm{L}_{8}$ ).

obtained using semi-synthetic medium, $Q_{P}=0.36$ g/L.h) (Table 2).

The ANOVA (design $\mathrm{L}_{16}$ ), for the $\mathrm{Q}_{\mathrm{P}}$ (Table 3) showed a reasonable correlation coefficient (75\%). Seventy four percent of the observed variation could be attributed to Factor E. The importance shown by this factor is explained by the fact that almost all treatments under acidic conditions led to low hydrolysate fermentability. The opposite effect was observed for the treatments carried out under alkaline conditions. Thus, increasing the $\mathrm{pH}$ value had a positive effect on ethanol volumetric productivity. To further analyze the influence of the other treatment conditions on the hydrolysate fermentability, the experimental design $\mathrm{L}_{16}$ assays were rearranged into a new experimental matrix, $\mathrm{L}_{8}$. In the new matrix, only the tests performed under alkaline conditions were considered.

There was a high correlation coefficient (94\%) in the variance analysis (ANOVA) of matrix $\mathrm{L}_{8}$. The high correlation demonstrates the significance of the particular factors evaluated for their influence on ethanol volumetric productivity. Variable $\mathrm{D}\left(\mathrm{O}_{3}\right)$ and the combination $\mathrm{BC}\left(\mathrm{H}_{2} \mathrm{O}_{2} / \mathrm{UV}\right)$ were significant at a confidence level of 90 and $95 \%$, respectively. Only variable D $\left(\mathrm{O}_{3}\right)$ had a positive effect on increasing the hydrolysate fermentability. The combination $\mathrm{BC}\left(\mathrm{H}_{2} \mathrm{O}_{2} / \mathrm{UV}\right)$ showed a negative effect, indicating that the use of UV radiation in the absence of $\mathrm{H}_{2} \mathrm{O}_{2}$ (or $\mathrm{H}_{2} \mathrm{O}_{2}$ in the absence of UV) can collaborate with the process because these conditions represent an adjustment of the interaction term BC at its lowest level (level 1).

The statistical analysis indicate that, in the experimental evaluated range, ozonation in alkaline medium
(pH 8) in the presence of $\mathrm{H}_{2} \mathrm{O}_{2}$ (treatment A3) or in the presence of UV radiation (treatment A5) were the most effective methods for the hydrolysate detoxification that in turn increase the yeast fermentability on rice straw hemicellulose hydrolysates. Further analysis such as scanning UV spectroscopy, infrared spectroscopy and were performed using hydrolysate treated according the assay A3.

\section{Ultraviolet spectra profiles of the hydrolysates treated by AOPs}

Absorbance within the ultraviolet spectrum is a technique that can provide information regarding the presence of phenolic compounds derived from lignin and furans resulting from the degradation of carbohydrates. This technique permits one to evaluate parameters including changes in concentration or even changes in the chemical structure of UV-absorbable molecules [2,39-41].

The differential spectrum technique is a methodology that helps interpret ultraviolet spectrum data. This technique can provide important information about the presence of ionizable groups, such as the phenolic hydroxyl group. These spectra are obtained by determining the scan profile of a sample in basic solution and zeroing the same sample in an acidic or neutral solution $[2,39]$.

The differential spectrum for phenolic hydroxyls exhibits three characteristic peaks with maxima near 250, 300 and $350-400 \mathrm{~nm}$. These peaks differ mainly due to the presence of phenolic hydroxyl groups that are conjugated (or not) with the aromatic carbonyl. The 
peak with a maximum between $350-400 \mathrm{~nm}$ is attributed to compounds having aromatic ring-mediated conjugation between the hydroxyl and the carbonyl, the peak with a maximum at approximately $300 \mathrm{~nm}$ is characteristic of non-conjugated hydroxyl groups and the peak with a maximum near $250 \mathrm{~nm}$ is attributed to the presence of both conjugated and non-conjugated structures [41,42].

Figure 4 shows the differential spectrum of the untreated hydrolysate and the hydrolysate treated by AOPs in the A3 assay. In the differential spectrum of the untreated RSHH (Figure 4), there were three maxima at 245, 295 and $350 \mathrm{~nm}$, indicating the presence of conjugated and non-conjugated phenolic hydroxyl groups. Variations were observed between the differential spectra of the treated hydrolysate from assay A3 and the untreated hydrolysate. After treatment, there were reductions in the three maxima (245, 295 and $350 \mathrm{~nm})$. These results demonstrate that the number of hydroxyl groups present in phenolic compounds was reduced upon treatment. Such reductions are related to changes in the aromatic hydroxyl groups or to ring cleavage resulting from the oxidative processes used.

\section{Evaluation of the infrared spectrum of the hydrolysates treated by AOPs}

The infrared spectra $\left(700-2000 \mathrm{~cm}^{-1}\right)$ of the rice straw hydrolysate media before and after treatment with the A3 assay conditions are shown in Figure 5. Each spectrum was standardized against the most intense signal (at approximately $1180 \mathrm{~cm}^{-1}$ ). The infrared spectrum of the untreated hydrolysate exhibited signals at 1720, 1640, 1326, $1286,1223,1178,1070,1008,886$, and $851 \mathrm{~cm}^{-1}$.
The treatment conditions employed in the A3 assay were able to change the signal intensities at multiple absorption peaks in the infrared spectrum of the treated hydrolysate. After treatment, the signal intensities at 1326, 1286, 1070, 1008, 886 and $851 \mathrm{~cm}^{-1}$ were reduced, there was an increase in the relative intensity of the absorption peak at $1223 \mathrm{~cm}^{-1}$, and shifts were observed at the $1178 \mathrm{~cm}^{-1}$ signal for the $1193 \mathrm{~cm}^{-1}$ wave number.

In general, the changes observed in the spectra of the treated hydrolysates demonstrate that the AOPs acted on the compounds derived from lignin, providing variations in the signal intensities at different wavelengths. Due to the complex mixture of different compounds, the signal changes may be associated with the selective degradation or removal of certain components or with chemical modifications and changes to the functional groups as a result of the treatments.

\section{Conclusions}

The AOPs treatments were able to preferentially removed compounds with high electron densities, such as furans and phenolic compounds, without affecting the sugar concentration in the rice straw hemicellulose hydrolysates. Among the different conditions of treatment with AOPs evaluated, ozonation in alkaline medium ( $\mathrm{pH} 8)$ in the presence of $\mathrm{H}_{2} \mathrm{O}_{2}$ (treatment A3) or UV radiation (treatment A5) were the most effective for hydrolysate detoxification and had a positive effect on increasing the yeast fermentability of rice straw hemicellulose hydrolysate. Under these conditions, the higher removal of total phenols (above 40\%), LMWPC (above 95\%) and furans (above 52\%) were observed. In addition, the ethanol volumetric productivity by $P$. stipitis was increased in

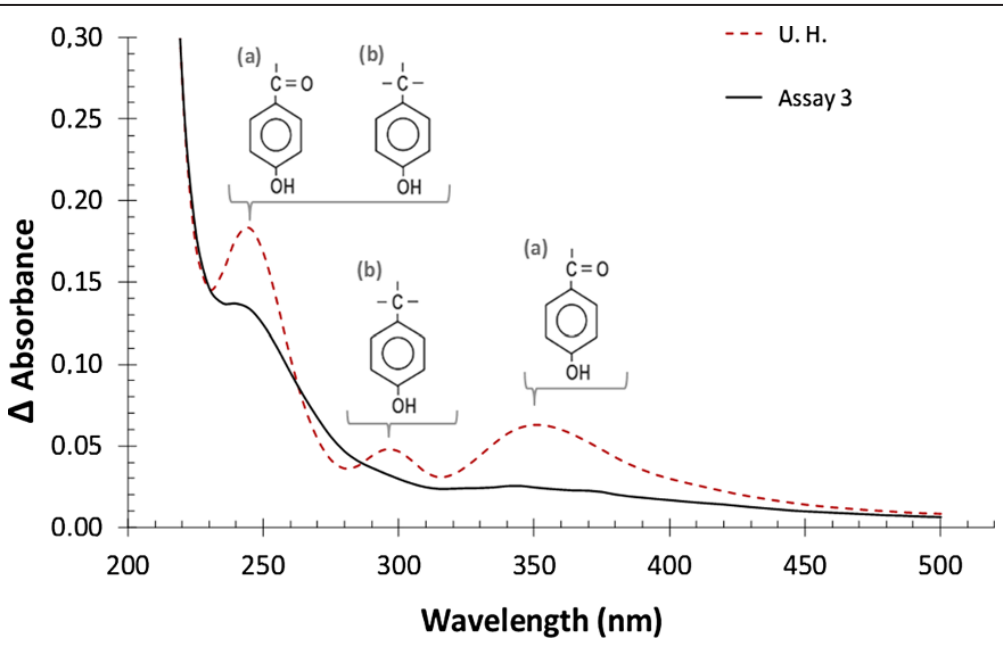

Figure 4 Ultraviolet differential spectrum profile before and after the detoxification treatment. Ultraviolet differential spectrum of the rice straw hemicellulosic hydrolysate before (- - ) and after (-) treatment by AOPs homogeneous in conditions of assay A3 of the experimental design. Phenolic hydroxyl groups conjugated (a) and non-conjugated (b) with the carbonyl through the aromatic ring. 




Figure 5 Infrared spectrum profile before and after the detoxification treatment. Infrared spectrum of the rice straw hemicellulosic hydrolysate before (- - ) and after (-) treatment by AOPs homogeneous in conditions of assay A3 of the experimental design.

approximately twice in relation the untreated hydrolysate. Based on the data, the AOPs can be considered promising methods to detoxify hydrolysates of lignocellulosic biomass for applications in bioconversion processes, and therefore is a field that deserves more attention.

\section{Materials and methods}

Preparation of rice straw hemicellulosic hydrolysate

Rice straw was collected from fields near Lorena city, São Paulo state, Brazil. The material was naturally dried in the sun until approximately $10 \%$ moisture content, milled to attain particles of about $1 \mathrm{~cm}$ in length and $1 \mathrm{~mm}$ in thickness, and stored. Hydrolysate was prepared by dilute acid hydrolysis as described by Roberto, Mussatto and Rodrigues [43]. Hydrolysis was performed in $50 \mathrm{~L}$ reactor, heated by electric resistance and agitated by rotation on own axis. The reaction was carried at $120^{\circ} \mathrm{C}$ for 30 minutes, $3 \mathrm{rpm}$ and the rice straw was impregnated with sulfuric acid solution (100 $\mathrm{mg} \mathrm{H}_{2} \mathrm{SO}_{4} / \mathrm{g}$ dry matter) in a 1:10 $(\mathrm{g} / \mathrm{mL})$ dry matter:acid solution ratio. After hydrolysis, the residual solid material was separated by centrifugation and the liquid phase (hemicellulosic hydrolysate) was submitted to a vacuum concentration process at $65^{\circ} \mathrm{C}$, in a $30 \mathrm{~L}$ stainless steel evaporator, aiming to increase the $\mathrm{xy}$ lose concentration about $120 \mathrm{~g} / \mathrm{L}$. The concentrated hydrolysate was stored at $4^{\circ} \mathrm{C}$ for later use.

\section{Hydrolysate treatment}

The rice straw hemicellulosic hydrolysate was submitted to different treatments conditions by homogeneous AOPs (Fenton, Photo-Fenton, $\mathrm{UV} / \mathrm{H}_{2} \mathrm{O}_{2}, \mathrm{O}_{3}$ and $\mathrm{UV} / \mathrm{O}_{3}$ ). The main characteristic of this group of AOPs is that all the chemical species responsible for radical hydroxyl generation are soluble in liquid phase. Experiments were carried out using an array of Taguchi $\mathrm{L}_{16}$ (Table 2), which consisted of 16 assays in which the variables: presence of $\mathrm{Fe}^{2+}, \mathrm{H}_{2} \mathrm{O}_{2}$, UV irradiation, $\mathrm{O}_{3}$, and $\mathrm{pH}$ were studied at two levels ( 1 and 2), as shown in Table 4. The observed responses were the change in sugar concentration, re- ducing the toxic compounds concentration and the fermentability of the treated hydrolysate.

The treatments were conducted in a glass reactor with a capacity of $150 \mathrm{~mL}$, equipped with water refrigeration and magnetic stirrer. Irradiation was performed using a germicidal lamp (UV-C) of $4 \mathrm{~W}$ of power, which is submerged in the reaction medium through a quartz bulb. Ozone was produced by conversion of $\mathrm{O}_{2}$ to $\mathrm{O}_{3}$ by corona effect, being a device used Ozone Generator Ozonebras, Z30 model with an output of $60 \mathrm{~W}$, at a flow rate of $1 \mathrm{~L} / \mathrm{min}$ of oxygen. All treatments were carried out for 30 minutes at a controlled temperature of $30^{\circ} \mathrm{C}$, under conditions which varied according to experimental design described below. Before the realization of the experimental design the concentrated rice straw hemicellulosic hydrolysate (Table 1) had the $\mathrm{pH}$ adjusted to values corresponding to the levels of the experimental design ( $\mathrm{pH} 8$ and 3) with $\mathrm{NaOH} 10 \mathrm{~mol} / \mathrm{L}$. The precipitate formed after each $\mathrm{pH}$ change was removed by centrifugation (1000 xg for 15 minutes), and then xylose concentration in the hydrolysate was adjusted to approximately $90 \mathrm{~g} / \mathrm{L}$.

Table 4 Values and levels of variables used in the experimental design

\begin{tabular}{lcc}
\hline Variables & \multicolumn{2}{c}{ Level } \\
\cline { 2 - 3 } & Not added* & $\mathbf{2}$ \\
\hline $\mathrm{Fe}^{2+}(\mathrm{A})$ & $0 \mathrm{mg} / \mathrm{L}$ & Addition of $50 \mathrm{mg} / \mathrm{L}$ \\
$\mathrm{H}_{2} \mathrm{O}_{2}$ (B) & Absence & $1000 \mathrm{mg} / \mathrm{L}$ \\
$\mathrm{UV}-\mathrm{C}(\mathrm{C})$ & $0 \mathrm{mg} / \mathrm{L}$ & Presence \\
$\mathrm{O}_{3}(\mathrm{D})$ & 3.0 & $500 \mathrm{mg} / \mathrm{L}^{* *}$ \\
$\mathrm{PH}(\mathrm{E})$ & 8.0
\end{tabular}

* Only the amount of $\mathrm{Fe}^{2+}$ present in the hydrolysate. ** Ozone dissolution of $2.5 \mathrm{mg} /$ minute (produced from a flow of $1 \mathrm{l} /$ minute of $\mathrm{O}_{2}$ ) for 30 minutes to a volume of $150 \mathrm{~mL}$ hydrolysate.

Values and levels of variables used in the Taguchi $L_{16}$ experimental design to evaluate the treatment of hydrolysate by homogeneous advanced oxidative process. 


\section{Fermentative process}

Fermentations were carried out in semi-synthetic or hydrolysate medium. Before the use of the rice straw hemicellulosic hydrolysate as a fermentation medium, its $\mathrm{pH}$ was changed to $\mathrm{pH} 5.5$ with $\mathrm{NaOH} 10 \mathrm{~mol} / \mathrm{L}$ or $\mathrm{H}_{2} \mathrm{SO}_{4} 10 \mathrm{~mol} / \mathrm{L}$ as required. After each change of $\mathrm{pH}$, the hydrolysate was centrifuged at $1000 \mathrm{xg}$ for 15 minutes to remove solid residue.

\section{Inoculum preparation}

Pichia stipitis NRRL Y-7124 was the microorganism used in the experiments. Cultures of this yeast were maintained on malt extract agar slants at $4^{\circ} \mathrm{C}$. For fermentations in semi-synthetic medium, inoculum was prepared by transfer of cells of the yeast in the maintenance medium to $125 \mathrm{~mL}$ Erlenmeyer flasks containing $25 \mathrm{~mL}$ of the medium composed by $(\mathrm{g} / \mathrm{L})$ : xylose (20.0), glucose (3.3), arabinose (3.3), urea (2.3), $\mathrm{MgSO}_{4} .7 \mathrm{H}_{2} \mathrm{O}$ (1.0) and yeast extract (3.0). For fermentations in hydrolysate, the inoculum was prepared also in the hydrolysate, whose concentrations of sugars were adjusted by dilution to (g/L): xylose (20.0), glucose (3.3), and arabinose (3.3); without the addition of yeast extract (3.0). The inoculated flasks were incubated in a rotary shaker at $30^{\circ} \mathrm{C}$ under stirring at $200 \mathrm{rpm}$ for 24 hours. After this time the cells were recovered by centrifugation (1100 xg for 20 minutes) and resuspended in sterile distilled water in order to obtain a concentrated suspension of cell which was used as inoculum.

\section{Media and fermentation conditions}

The semi-synthetic medium was composed by $(\mathrm{g} / \mathrm{L})$ : $\mathrm{xy}-$ lose (70.0), glucose (12.0), arabinose (12.0), urea (2.3), $\mathrm{MgSO}_{4} .7 \mathrm{H}_{2} \mathrm{O}(1.0)$ and yeast extract (3.0). The hydrolysate based medium was composed by $(\mathrm{g} / \mathrm{L})$ : xylose $(70.0)$, glucose (12.0), arabinose (12.0) with addition of yeast extract $(3 \mathrm{~g} / \mathrm{L})$. The fermentations were carried out in $125 \mathrm{~mL}$ Erlenmeyer flasks containing $50 \mathrm{~mL}$ of fermentation medium and inoculated with $1 \mathrm{~g} / \mathrm{L}$ of cells. The flasks were incubated in a rotary shaker at a temperature of $30^{\circ} \mathrm{C}$ and shaken at $200 \mathrm{rpm}$ for 120 hours.

\section{Analytical methods}

Glucose, xylose, arabinose, acetic acid, and ethanol concentrations were determined by high performance liquid chromatography (HPLC) in Waters chromatograph equipped with a refractive index detector and a Bio-Rad Aminex HPX-87H column $(300 \times 7.8 \mathrm{~mm})$. Operation conditions included: temperature of $45^{\circ} \mathrm{C}, 0.005 \mathrm{M}$ sulfuric acid as eluent in a flow of $0.6 \mathrm{~mL} / \mathrm{min}$, and sample volume of $20 \mu \mathrm{L}$. The cellular growth was determined by measuring the fermentation broth at UV-spectrophotometric absorbance at $600 \mathrm{~nm}$, which was correlated to a calibration curve (dry weight $\times$ optical density).
Furfural, hydroxymethylfurfural, vanillic acid, vanillin, $p$-coumaric acid, and ferulic acid were also determined by HPLC, using an UV detector (at $276 \mathrm{~nm}$ ) and a ZORBAX Eclipse Plus C18 column $(4.6 \times 100 \mathrm{~mm}$ and $3.5 \mu \mathrm{m}$ particle size) at room temperature, acetonitrile/ water/acetic acid at a ratio of $88: 11: 1$ as the eluent, a flow rate of $0.8 \mathrm{~mL} / \mathrm{min}$ and sample volume of $20 \mu \mathrm{L}$. The concentration of total phenolic compounds was estimated by Folin-Ciocalteau method [44] using ferulic acid as standard. Ultraviolet spectrum of the hydrolysate was determined in Hitachi U-2000 spectrophotometer, in the range of $500-200 \mathrm{~nm}$, with a pitch of $5 \mathrm{~nm}$ using quartz cuvettes. The determination of the spectrum was made with hydrolysate diluted with alkaline water $(\mathrm{pH}$ around 12), and distilled water used as a blank. The differential scanning spectra were obtained by determining the profile scan of the hydrolysate in alkaline media ( $\mathrm{pH} 12)$, using as zero the same sample, but in acidic media ( $\mathrm{pH} 2$ ). The infrared spectra, $2000-700 \mathrm{~cm}^{-1}$ were determined in a spectrophotometer Perkin Elmer Spectrum One. The hydrolysate was submitted to a solid-liquid extraction in Sep-Pak C18 (Waters) for the separation of the phenolic compounds (retained on Sep-Pak), which was recovered and used to determine the infrared spectra. The samples were prepared by mixing one drop of the fraction recovered $100 \mathrm{mg}$ of $\mathrm{KBr}$, which was dried in desiccators under vacuum over $\mathrm{P}_{2} \mathrm{O}_{5}$. The dried samples were processed in $\mathrm{KBr}$ tablet compressing it at a pressure of $10 \mathrm{kgf. \textrm {cm } ^ { 2 }}$. Inserts made of pure $\mathrm{KBr}$ were used as reference.

Ethanol yield was expressed as\% of the ratio between ethanol concentration produced and the theoretical maximum ethanol based on total content of fermentable sugars. Ethanol volumetric productivity ( $\left.Q_{B}, g / L . h\right)$ was calculated as the ratio between the ethanol concentration $(\mathrm{g} / \mathrm{L})$ and the fermentation time $(\mathrm{h})$.

\begin{abstract}
Abbreviations
AOPs: Advanced Oxidative Processes; RSHH: Rice Straw Hemicellulosic Hydrolysate; HMF: Hydroxymethylfurfural; HPLC: High performance liquid chromatography; LMWPC: Low molecular weight phenolic compounds; UV: Ultraviolet radiation; $\mathrm{H}_{2} \mathrm{O}_{2}$ : Hydrogen peroxide; $\mathrm{O}_{3}$ : Ozone; $\mathrm{O}_{2}$ : Oxygen; $\mathrm{H}_{2} \mathrm{SO}_{4}$ : Sulfuric acid; $\mathrm{Fe}^{2+}$ : Iron divalent ion; $\mathrm{NaOH}$ : Sodium hydroxide; $\mathrm{KBr}$ : Potassium bromide; $\mathrm{P}_{2} \mathrm{O}_{5}$ : Phosphorus pentoxide; ANOVA: Analysis of variance; $Q_{p}$ : Ethanol volumetric productivity; SM: Semi-synthetic medium; UH: Untreated rice straw hemicellulosic hydrolysate.
\end{abstract}

\section{Competing interests}

The authors declare that they no competing interests.

\section{Authors' contributions}

JPAS participated in the design of the study, carried out the experiments, acquired the data and drafted the manuscript. LMC participated in the design of the study, co-conducted the experimental works and participated in the result interpretation. ICR participated in the design of the study, participated in the results interpretation and analysis, and critically revised the manuscript for important intellectual content. All authors read and approved the final manuscript. 


\section{Acknowledgement}

The authors gratefully acknowledge financial support from Fundação de Amparo à Pesquisa do Estado de São Paulo (FAPESP), Coordenação de Aperfeiçoamento de Pessoal de Nível Superior (CAPES), and Conselho Nacional de Desenvolvimento Cientifico e tecnológico (CNPq) - BRAZIL.

Received: 28 September 2012 Accepted: 31 January 2013

Published: 15 February 2013

\section{References}

1. Pauly M, Keegstra K: Cell-wall carbohydrates and their modification as a resource for biofuels. Plant J 2008, 54:559-568.

2. Lewin M, Goldstain IS: Wood Structure and Composition. New York: CRC Press; 1991.

3. Fengel D, Weneger G: Wood: Chemistry, Ultra-Structure, Reactions. Berlin: Walter de Gruyter; 1989.

4. Goldstein IS: Organic Chemicals from Biomass. Boca Raton: CRC Press; 1981.

5. Binod P, Sindhu R, Singhania RR, Vikram S, Devi L, Nagalakshmi S, Kurien N, Sukumaran RK, Pandey A: Bioethanol production from rice straw: an overview. Bioresour Technol 2010, 101:4767-4774.

6. Mussatto SI, Roberto IC: Alternatives for detoxification of diluted-acid lignocellulosic hydrolyzates for use in fermentative processes: a review. Bioresour Technol 2004, 93:1-10.

7. Arslan S, Saraçoglu NE: Effect of pretreatment methods for hazelnut shell hydrolysate fermentation with Pichia stipitis to ethanol. Bioresour Technol 2010, 101:8664-8670.

8. Chandel AK, Kapoor RK, Singh A, Kuhad RC: Detoxification of sugarcane bagasse hydrolysate improves ethanol production by Candida shehatae NCIM 3501. Bioresour Technol 2007, 98:1947-1950.

9. Villarreal MLM, Prata AMR, Felipe MGA, Silva JBA: Detoxification procedures of eucalyptus hemicellulose hydrolysate for xylitol production by Candida guilliermondii. Enzyme Microb Technol 2006, 40:17-24.

10. López MJ, Nichols NN, Dien BS, Moreno J, Bothast RJ: Isolation of microorganisms for biological detoxification of lignocellulosic hydrolysates. Appl Microbiol Biotechnol 2004, 64:125-131.

11. Lee JM, Venditti AR, Jameel H, Kenealy WR: Detoxification of woody hydrolyzates with activated carbon for bioconversion to ethanol by the thermophilic anaerobic bacterium Thermoanaerobacterium saccharolyticum. Biomass Bioenergy 2011, 35:626-636.

12. Zhuang J, Liu Y, Wu Z, Sun Y, Lin L: Hydrolysis of wheat straw hemicellulose and detoxification of the hydrolysate for xylitol production. BioResources 2009, 4(2):674-686

13. Carvalho RJ, Marton JM, Silva F, Felipe MG: Avaliação do sistema combinado de tratamento do hidrolisado hemicelulósico de bagaço de cana-de- açúcar com carvão ativo e resinas de troca iônica para sua utilização como meio de fermentação. Revista Analytica 2005, 18:48-55.

14. Zhu J, Yong $Q, X u Y, Y u$ S: Detoxification of corn stover prehydrolyzate by trialkylamine extraction to improve the ethanol production with Pichia stipitis CBS 5776. Bioresour Technol 2011, 102:1663-1668.

15. Alriksson B, Cavka A, Jönsson L: Improving the fermentability of enzymatic hydrolysates of lignocelluloses through chemical in-situ detoxification with reducing agents. Bioresource Technolog 2011, 102:1254-1263.

16. Martinez A, Rodrigues ME, Wells ML, York SW, Preston JF, Ingram LO: Detoxification of dilute acid hydrolysates of Lignocellulose with lime. Biotechnol Prog 2001, 17:287-293.

17. Palmqvist $E$, Hahn-Hägerdal B: Fermentation of lignocellulosic hydrolyzates. I: inhibition and detoxification. Bioresour Technol 2000, 74:25-33.

18. Telli-Okur M, Eken-Saraçoglu N: Fermentation of sunflower seed hull hydrolysate to ethanol by Pichia stipitis. Bioresour Technol 2008, 99:2162-2169.

19. Larsson S, Reimann A, Nilvebrant NO, Jonsson LJ: Comparison of different methods for the detoxification of Lignocellulose hydrolyzates of spruce. Appl Biochem Biotechnol 1999, 77-79:91-103.

20. Eken-Saraçoglu N, Arslan Y: Comparison of different pretreatments in ethanol fermentation using corn cob hemicellulosic hydrolysate with Pichia stipitis and Candida shehatae. Biotechnol Lett 2000, 22:855-858.

21. Mussatto SI, Santos JC, Roberto IC: Effect of pH and activated charcoal adsorption on hemicellulosic hydrolysate detoxification for xylitol production. J Chem Technol Biotechnol 2004, 79:590-596.

22. Ramos WLS, Poznyak T, Chairez I, Córdova Rl: Remediation of lignin and its derivatives from pulp and paper industry wastewater by the combination of chemical precipitation and ozonation. J Hazard Mater 2009, 169:428-434.
23. Glaze WH, Kang JW, Chapin DH: The chemistry of water treatment processes involving ozone, hydrogen peroxide and ultraviolet radiation. Ozone Sci Eng 1987, 9:335-352.

24. Ahmed B, Mohamed H, Limem E, Bensalah N: Degradation and mineralization of organic pollutants contained in actual pulp and paper mill wastewaters by a UV/ $/ \mathrm{H}_{2} \mathrm{O}_{2}$ process. Ind Eng Chem 2009, 48:3370-3379.

25. Pacheco JR, Peralta-Zamora PG: Integration of physical chemistry and advanced oxidative processes for remediation of landfill leachate. Engenharia Sanitária e Ambiental 2004, 9(4):306-311.

26. Nogueira RFP, Trovó AG, Silva MRA, Villa RD, Oliveira MCO: Fundamentos e aplicações ambientais dos processos Fenton e foto-Fenton. Química Nova 2007, 30(2):400-408.

27. Freire $R S$, Pelegrini $R$, Kubota $L T$, Durán $N$ : Novas tendências para o tratamento de resíduos industriais contendo espécies organocloradas. Química Nova 2000, 23(4):504-511.

28. Legrini O, Oliveros E, Braun AM: Photochemical processes for water treatment. Chem Rev 1993, 93:671-698.

29. Lanzalunga O, Bietti M: Photo- and radiation chemical induced degradation of lignin model compounds. Journal of Photochemistry and Photobiology B: Biology 2000, 56:85-108.

30. Guimarães JR, Almeida Junior RL, Maniero MG, Fadini PS: Ozonização em meio básico para redução de cor do licor negro de indústria de celulose de algodão. Engenharia Sanitária e Ambiental 2010, 15(1):93-98.

31. Chamarro E, Marco A, Esplugas S: Use of Fenton reagent to improve organic chemical biodegradability. Water Res 2001, 35(4):1047-1051.

32. Reyes J, Dezotti M, Mansilla H, Villasenõr J, Esposito E, Durán N: Biomass photochemistry-XXII: combined photochemical and biological process for treatment of Kraft E1 effluent. Appl Catal Environ 1998, 15:211-219.

33. Meriç S, Kaptan D, Olmez T: Color and COD removal wastewater containing Reactiva Black 5 using Fenton's oxidation process. Chemosphere 2004, 54:435-441.

34. Palmqvist $E$, Hahn-Hägerdal B: Fermentation of lignocellulosic hydrolyzates. II: inhibitors and mechanisms of inhibition. Bioresour Technol 2000, 74:25-33.

35. Carvalho GBM, Mussatto SI, Candido EJ, Silva JBS: Comparison of different procedures for the detoxification of eucalyptus hemicellulosic hydrolysate for use in fermentative processes. J Chem Technol Biotechnol 2006, 81:152-157.

36. Machado AEH, Ruggiero R, Neumann MG: Fotodegradação de ligninas acelerada por peróxido de hidrogênio: evidências de participação do ${ }^{1} \mathrm{O}_{2}\left({ }^{1} \Delta_{g}\right)$ nas reações em meio alcalino. Química Nova 1994, 17(2):111-118.

37. Gernjak W, Krutzler T, Glaser A, Malato S, Caceres J, Bauer R, Fernández-Alba AR: Photo-Fenton treatment of water containing natural phenolic pollutants. Chemosphere 2003, 50:71-78.

38. Ragnar $\mathrm{M}$, Lindgren $\mathrm{CT}$, Nilvebrant NO: $\mathrm{pk}_{\mathrm{a}}$-values of guaiacyl and syringyl phenols related to lignin. Journal of Wood Chemistry and Technology 2000, 20(3):277-305.

39. Hon DNS, Shiraishi N: Wood and Cellulosic Chemistry. New York: Marcel Dekker; 2001.

40. Martinez A, Rodriguez ME, York SW, Preston JF, Ingram LO: Use of UV absorbance to monitor furans in dilute acid hydrolysates of biomass. Biotechnol Prog 2000, 16:637-641.

41. Goldschimid O: Determination of phenolic hydroxyl content of lignin preparations by ultraviolet spectrophotometry. Anal Chem 1954, 26(9):1421-1423.

42. Mansouri NEE, Salvadó J: Analytical methods for determining functional Groups in various technical lignins. Ind Crop Prod 2007, 26:116-124.

43. Roberto IC, Mussatto SI, Rodrigues RCLB: Dilute-acid hydrolysis for optmization of xylose recovery from rice straw in a semi-pilot reactor. Ind Crop Prod 2003, 17:171-176.

44. Singleton V, Orthofer R, Lamuela-Raventós R: Analysis of total phenols and other oxidation substrates and antioxidants by means of folin-ciocalteus reagent. Methods Enzymol 1999, 299:152-178.

doi:10.1186/1754-6834-6-23

Cite this article as: Silva et al.: Treatment of rice straw hemicellulosic hydrolysates with advanced oxidative processes: a new and promising detoxification method to improve the bioconversion process.

Biotechnology for Biofuels 2013 6:23. 